\title{
ELECTROLUMINESCENT MATERIAL FOR FLAT PANEL DISPLAY
}

\author{
Final Report \\ for CRADA No. ORNL95-0371 \\ with \\ OSRAM Sylvania, Inc.
}

D. B. Smith

M. R. Cates

Oak Ridge National Laboratory

and

R. G. W. Gingerich

OSRAM Sylvania, Inc.

Date Published - October 2000

\author{
Prepared for the \\ Office of Nuclear Energy, Science and \\ Technology \\ Technology Partnerships Program \\ of the \\ Department of Energy \\ Prepared by the \\ Oak Ridge National Laboratory \\ Oak Ridge, Tennessee 37831-8048 \\ Managed by \\ UT-BATTELLE \\ for the \\ U.S. DEPARTMENT OF ENERGY \\ under contract DE-AC05-00OR22725
}

Approved for Public Release 


\section{DISCLAIMER}

This report was prepared as an account of work sponsored by an agency of the United States Government. Neither the United States Government nor any agency thereof, or any of their employees, makes any warranty, expressed or implied, or assumes any legal liability for responsibility for any third party's use, or the results of such use, of any information, apparatus, product or process disclosed in this report, or represents that its use by such third party would not infringe privately owned rights. Reference herein to any specific commercial produce, process, or service by trade name, trademark, manufacturer, or otherwise, does not necessarily constitute or imply its endorsement, recommendation, or favoring by the United States Government or any agency thereof. The views and opinions of authors expressed herein do not necessarily state or reflect those of the United States Government or any agency thereof. 
ORNL/M-6539

ELECTROLUMINESCENT MATERIAL FOR FLAT PANEL DISPLAY

\author{
Final Report \\ for CRADA No. ORNL95-0371 \\ with \\ OSRAM Sylvania, Inc.
}

D. B. Smith

M. R. Cates

Oak Ridge National Laboratory

and

R. G. W. Gingerich

OSRAM Sylvania, Inc.

Date Published - October 2000

\author{
Prepared for the \\ Office of Nuclear Energy, Science and Technology \\ Technology Partnerships Program \\ of the \\ Department of Energy \\ Prepared by the \\ Oak Ridge National Laboratory \\ Oak Ridge, Tennessee 37831-8048 \\ Managed by \\ UT-BATTELLE \\ for the \\ U.S. DEPARTMENT OF ENERGY \\ under contract DE-AC05-00OR22725
}

Approved for Public Release 


\section{TABLE OF CONTENTS}

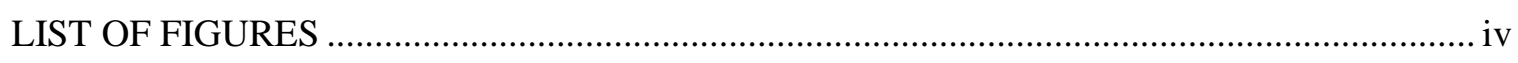

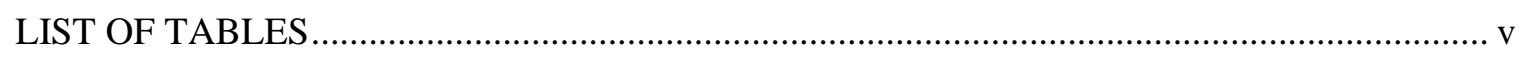

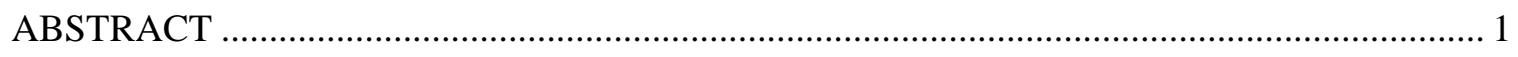

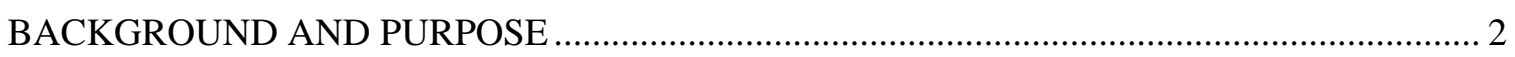

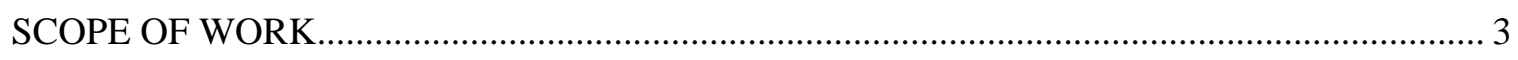

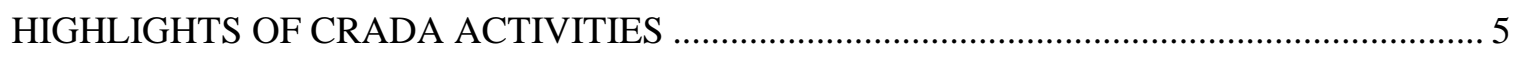

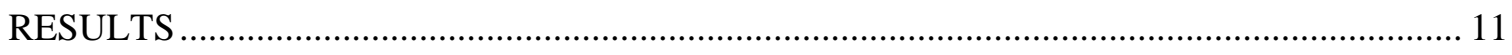

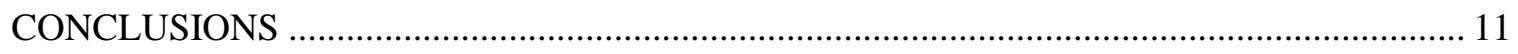

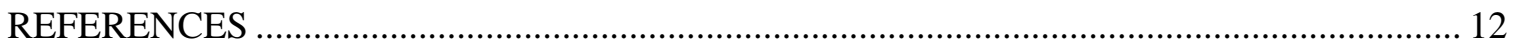




\section{LIST OF FIGURES}

Fig. 1. Pulsed laser deposition apparatus used to produce composite EL films............................. 7

Fig. 2. Ablation plume formed during pulsed laser deposition ................................................. 8

Fig. 3. Scanning electron microscope image of composite bi-layered EL film............................... 8

Fig. 4. Sputtered neutral mass spectrometer scan of sample BTZ 0129................................... 9 


\section{LIST OF TABLES}

Table 1. List of composite EL films fabricated and tested during CRADA project..................... 10 


\begin{abstract}
The purpose of this Cooperative Research and Development Agreement (CRADA) was to develop a new-generation electroluminescent (EL) material for flat panel displays and related applications by using unique and complementary research capabilities at Oak Ridge National Laboratory and OSRAM Sylvania, Inc. The goal was to produce an EL material with a luminance 10 times greater than conventional EL phosphors. An EL material with this increased luminance would have immediate applications for flat panel display devices (e.g., backlighting for liquid-crystal diodes) and for EL lamp technology. OSRAM Sylvania proposed that increased EL phosphor luminance could be obtained by creating composite EL materials capable of alignment under an applied electric field and capable of concentrating the applied electric field. Oak Ridge National Laboratory used pulsed laser deposition as a method for making these composite EL materials. The materials were evaluated for electroluminescence at laboratory facilities at OSRAM Sylvania, Inc. Many composite structures were thus made and evaluated, and it was observed that a composite structure based on alternating layers of a ferroelectric and a phosphor yielded electroluminescence. An enabling step that was not initially proposed but was conceived during the cooperative effort was found to be crucial to the success of the composite structure. The CRADA period expired before we were able to make quantitative measurements of the luminance and efficiency of the composite EL material. Future cooperative work, outside the scope of the CRADA, will focus on making these measurements and will result in the production of a prototype composite EL device.
\end{abstract}




\section{BACKGROUND AND PURPOSE}

The purpose of this Cooperative Research and Development Agreement (CRADA) was to develop a new-generation electroluminescent (EL) material for use in flat panel displays and related display applications. The CRADA project combined unique capabilities and intellectual property contributed by Oak Ridge National Laboratory (ORNL) and OSRAM Sylvania, Inc. (OSI). OSI holds a patent ${ }^{1}$ on the composition of a new type of EL material and a patent ${ }^{2}$ on a method for making an improved EL device from this material. Oak Ridge National Laboratory holds two patents ${ }^{3}$ on the deposition technology that enabled the fabrication of the new EL material. The overall goal of the project was to develop an improved EL material that is 10 times brighter than conventional EL materials.

Electroluminescence refers to the non-thermal emission of light that occurs when an electric field is applied to certain materials. Thus an EL display device uses electroluminescence as the mechanism for producing visible light. There are two basic types* of EL device structures: thinfilm EL devices and thick-film EL devices. The conventional thin-film layer design (a doubleinsulating-layer structure) consists of an EL phosphor sandwiched between ferroelectric and conducting thin-film layers. Thin-film EL devices are characterized by poor luminance and poor luminous efficiency. The luminescence of an EL phosphor may be increased substantially if the effective electric field applied across the phosphor is increased. One way to increase the effective electric field across the EL phosphor is to decrease the distance across which the voltage is applied. This means the EL phosphor film must be as thin as possible (generally less than about 0.5 micrometers thick). The minimum film thickness (and the maximum applied voltage) is determined by the requirement that the film must not undergo dielectric breakdown.

The conventional thick-film (or powder) EL structure consists of an EL phosphor in an organic binder that is applied to a substrate as a thick layer (typically 5-20 micrometers thick). The luminance and luminous efficiency of thick-film EL devices are better than those of thin-film devices, but they are nonetheless unsatisfactory for use in flat panel EL displays or for backlighting in color liquid crystal diode displays. The luminance produced by thick-film EL devices is adequate for backlighting in monochromatic liquid-crystal diode displays.

The work done under this CRADA was based on a recently developed theory for EL films which predicts that a dramatic increase in luminance may be obtained by creating a composite EL material. This composite EL material consists of alternating layers of EL phosphor, dielectric and conductive materials. The EL phosphor layers are very thin and provide the desired increased electric field. The alternating layers of materials are repeated multiple times to produce a thick thin-film device structure. After fabrication, the composite material is fractionated (pulverized) into a powder and incorporated into a thick film EL device. The fractionated EL material has the additional benefit of being capable of alignment under the applied electric field. Hence the resulting composite EL material device has the advantages of both the thin-film and thick-film EL device structures.

The cooperative effort consisted of fabricating and testing composite EL materials. Conventional physical vapor deposition techniques for depositing EL materials, such as electronbeam evaporation, sputtering or atomic layer epitaxy, were not suitable for fabricating this new material due to its complex and repetitive structure. Pulsed laser deposition (PLD) was an ideal

\footnotetext{
* The two basic device structures can each be subdivided into ac-drive and dc-drive designs for a total of four EL device structures. We envision the new EL material for use in ac-drive EL devices.
} 
choice because PLD provides rapid deposition of the required materials in a highly controllable fashion. The PLD -phase material is deposited on a substrate in a highly controlled fashion.

After fabrication, the composite films were fractionated and incorporated into an EL test cell.

After fabrication, the complete film is fractionated and incorporated into an EL device. When fully developed, this device should yield a brightness that is an order of magnitude larger than conventional EL devices. We predict that this device will be as bright as a fluorescent lamp and will have a useful lifetime of 10,000 hours.

It is hoped that the material under development will ultimately yield a luminance that is an order of magnitude larger than conventional EL devices. Because it incorporates a thin-film EL device structure, we predict that it will have a useful lifetime of 10,000 hours or longer. If these goals are met the technology will contribute to the U.S. competitive lead in flat panel display materials and technology. It will be of benefit to DOE in that the new electroluminescent materials will enable more efficient lighting products, thus providing the same luminescence with considerably less electrical power. The project will be a cooperative research effort between a DOE laboratory and a U.S. industrial partner that has enormous potential for scientific advancement and commercial benefit. The result for the industry partner will be increased sales of their product for both new and existing markets.

\section{SCOPE OF WORK}

The starter materials from which the composite electroluminescent materials were made were contributed by OSI. OSI synthesized or purchased these starter materials (EL phosphors, barium titanate, and various conductors) and had them processed them into targets for ORNL's pulsed laser deposition apparatus. ORNL used the materials to fabricate the necessary multilayers and performed some screening test and evaluations.

ORNL delivered the most suitable multilayer specimens to OSI for characterization and electroluminescence testing. OSI has extensive analytical facilities including, for example, X-ray diffraction and fluorescence monitoring equipment, mass spectrometry instrumentation, and associated materials characterization hardware. OSI processed the samples by carefully fractionating the material and then testing the material in an oil-suspension cell designed to evaluate electroluminescence.

The project was initially arranged as a series of tasks. The tasks involved fabricating and evaluating two-layer films, three-layer films, and four layer films; then evaluating results and incorporating improvements into composite EL materials for a prototype display device.

Task 1: Produce and Evaluate Two-Component Films

ORNL was responsible for the production and evaluation of a repetitive two-layer entity composed of a film of ferroelectric barium titanate $\left(\mathrm{BaTiO}_{3}\right)$, approximately 50 to $500 \mathrm{~nm}$ in thickness, and an electroluminescent layer composed of doped zinc sulfide, approximately 50 to $500 \mathrm{~nm}$ in thickness. The dopant required for yellow emission (manganese) was used. This bilayer structure was repeated until a total layer thickness of about 10 micrometers was achieved. The bi-layer structure was deposited onto a silicon wafer substrate which allowed the structure to 
be easily separated for fractionation and evaluation in an oil-suspension cell. The fractionation and evaluation was performed at OSI.

Task 2: Produce and Evaluate Three-Component Films

This task involved the fabrication of a repetitive three-layer electroluminescent structure that is composed of:

(i) a film of aluminum (approximately 50 to 500 nanometers in thickness);

(ii) a film of ferroelectric barium titanate (approximately 50 to 500 nanometers in thickness); and

(iii) films of appropriately doped zinc sulfide (approximately 50 to 500 nanometers in thickness).

This repeating tri-layer structure of about 7 micrometers in thickness was to be deposited on a substrate from which the three-component film can be easily separated for fractionation and testing in an oil-suspension cell. The evaluations were to be performed at OSI.

Task 3: Produce and Evaluate Four-Component Films

This task involved the fabrication of a repetitive four-layer electroluminescent structure that is composed of:

(i) a film of aluminum (approximately 50 to 500 nanometers in thickness).

(ii) a film of ferroelectric barium titanate (approximately 50 to 500 nanometers in thickness),

(iii) a film (for each of the four colors) of appropriately doped zinc sulfide (approximately 50 or 500 nanometers in thickness), and

(iv) a film of ferroelectric barium titanate (approximately 50 or 500 nanometers in thickness).

This repeating quad-layer entity of about 7 micrometers in thickness was to be deposited on a substrate from which the four-component film can be easily separated for fractionation and testing in an oil-suspension cell. The evaluations were to be performed at OSI.

\section{Task 4: Optimization and Final Report}

The overall approach was to be evaluated, improvements incorporated into the composite film structures, and a upgrade prototype EL device demonstrated by OSI. A final report was to be issued. The entire project was to be completed 24 months after initiation. 


\section{HIGHLIGHTS OF CRADA ACTIVITIES}

The first achievement of the CRADA project was the demonstration that the pulsed laser deposition technique could produce the required multilayer composite films. This achievement was reported in the progress report ${ }^{4}$ issued after the first project year. Several interesting challenges were encountered and successfully treated during this early part of the project. Parametric studies of pulsed laser deposition of the EL materials lead to a technique that provided reproducible results in film composition, layer thickness uniformity, and separation of adjacent layers.

The pulsed laser deposition apparatus used to fabricate the composite EL films is shown in Fig. 1. The apparatus consists of an excimer laser for ablation of the target materials, an optical system to steer and focus the laser beam, a film deposition chamber, and the electronics and computer necessary for monitoring and controlling the process.

The excimer laser is visible on the right-hand side of the top photograph in Fig. 1. We used a krypton-fluoride gas mix in the laser to produce a 248-nm emission for the laser ablation. The proprietary beam delivery optics scheme (beam splitter, mirrors, lenses) is housed in the black enclosure between the laser and the deposition chamber (Fig. 1 and Fig. 2). The deposition chamber-the stainless steel vacuum chamber in the center of both photographs-contained the proprietary LARES target holder carousel. (LARES is an acronym for Laser Ablation from Rapidly Exchanged Sources). The LARES target holder carousel rotated at a rate of 10 cycles per second, and we operated the laser at 10 pulses per second in synchronization with the rotation rate of the carousel.

The photographs in Fig. 2 show the fluorescing plume of material that was ablated from a barium titanate target during a single laser pulse. In the bottom photograph the view is looking down on the deposition process through a pyrex window on the top flange of the deposition chamber. In this view the plume is moving from the target on the left to the deposition substrate on the right. The bluish fluorescence is due to collisional excitation of the low-pressure background gas by the species in the plume. The silicon wafer substrate is in the form of a circular disk and is mounted on the substrate heater using conductive paste for optimum heat transfer. The two (invisible) laser beams overlap to produce a beam spot on the deposition target and are incident on the target at angles oblique to the plume normal. The top photograph in Fig. 2 shows a view of the ablation plume from a pyrex window on a side flange of the deposition chamber. The LARES target holder carousel is just visible at the extreme right-hand-side of the window.

After the deposition process was established, we verified that it was possible to remove the composite films from the substrate for fractionization without damaging the repetitive multilayering in the films. We found that 3 -cm-diameter silicon wafers provided an adequate substrate for post-deposition film removal. We heated the substrates to temperatures high enough to provide good film morphology yet substantially below the temperature at which the phosphors are known to decompose.

Some preliminary evaluation of each composite film sample was done before it was sent to OSI for characterization, fractionation and evaluation of EL. We used optical and scanning electron microscopy to examine the composite film structure for layer separation and to determine its approximate total thickness. Fig. 3 shows a scanning electron micrograph of a repetitive twolayer structure of barium titanate and manganese-doped zinc sulfide. The film's cross-sectional 
profile runs from top left to bottom right. The sharpness of the layer demarcation is typical of the best composite films we made during the project.

OSI evaluated each film sample using electron spectroscopy for chemical analysis (ESCA) or Sputtered Neutral Mass Spectrometery (SNMS) or both. These analytical techniques provided information on the chemical composition of the film samples and the thickness and demarcation of the deposited layers. A SNMS spectrum of a repetitive two-layer film sample is shown in Fig. 4. In this spectrum the repetitive bi-layer structure of the film is evidenced by the oscillating intensities of the atomic species: the presence of the barium titanate atoms $(\mathrm{Ba}, \mathrm{Ti}, \mathrm{O})$ is exactly out of phase with the atoms in the manganese-doped zinc sulfide phosphor ( $\mathrm{Zn}, \mathrm{S}, \mathrm{Mn}$ ).

OSI evaluated each film sample for electroluminescence using an oil-suspension cell. The fractionated film was mixed into castor oil and placed in the oil-suspension cell. The completed oil-suspension cell was then connected to a high-voltage, variable frequency, sine-wave oscillator for excitation. Luminance measurements were performed with a photometer on the EL cell operating at 60 and 400 cycles per second $(\mathrm{Hz})$ and at voltages of 150, 200, and 400V. A 6000 $\mathrm{Hz}$ high-frequency test at $150 \mathrm{~V}$ was also recorded. Although luminance values are measured in foot-Lamberts, the relative percent brightness between a control phosphor and a sample measured sequentially is commonly reported. In addition, the CIE chromaticity coordinates, $x$ and $\mathrm{y}$, are recorded at $60 \mathrm{~Hz}$ and $400 \mathrm{~Hz}$ at 200 volts, by use of a spectroradiometer.

Table 1 lists the composite EL films fabricated and tested during the CRADA project. The sample designated BTZC 0811 was the first composite structure to produce electroluminescence. Electroluminescence was first observed at $400 \mathrm{~Hz}$ and $500 \mathrm{~V}$, and the brightness increased as the frequency increased up to $900 \mathrm{~Hz}$. 

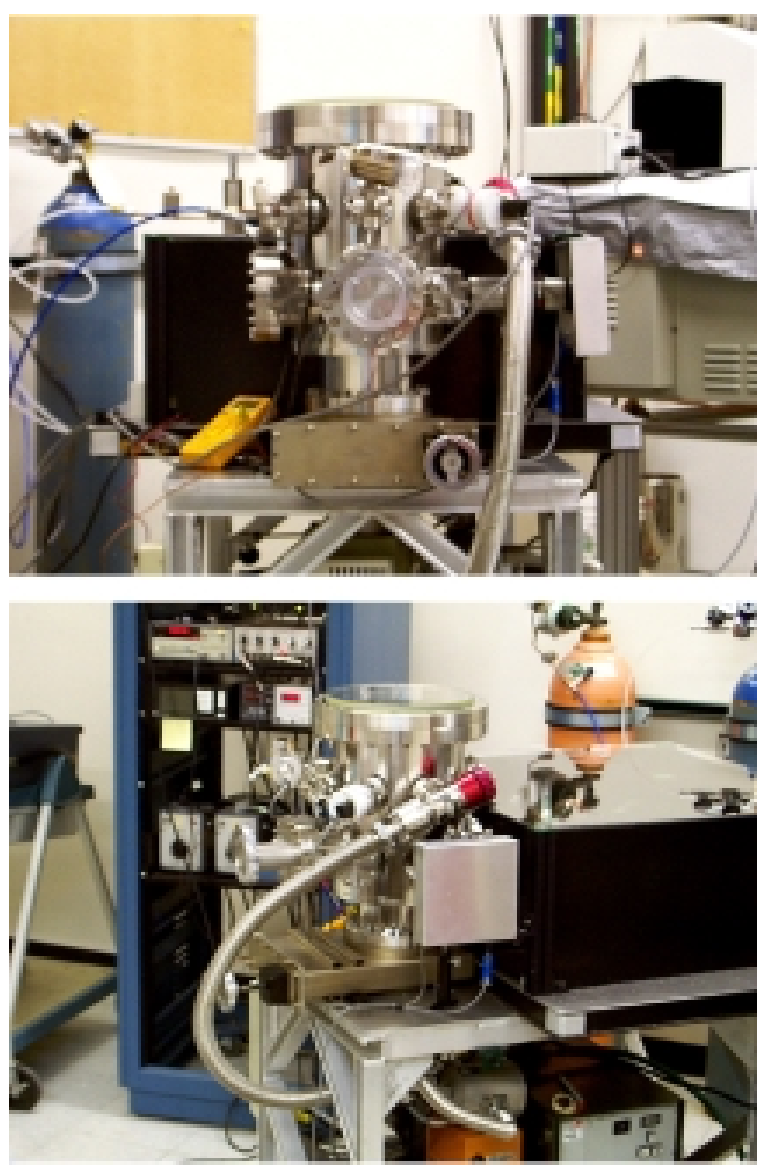

Fig. 1. Pulsed laser deposition apparatus used to produce composite EL films. 

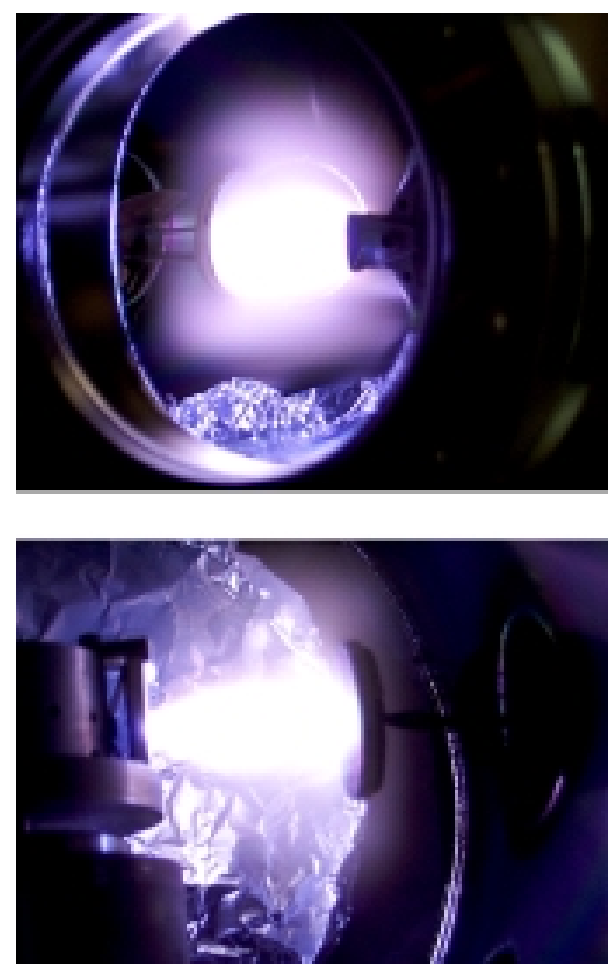

Fig. 2. Ablation plume formed during pulsed laser deposition of barium titanate.

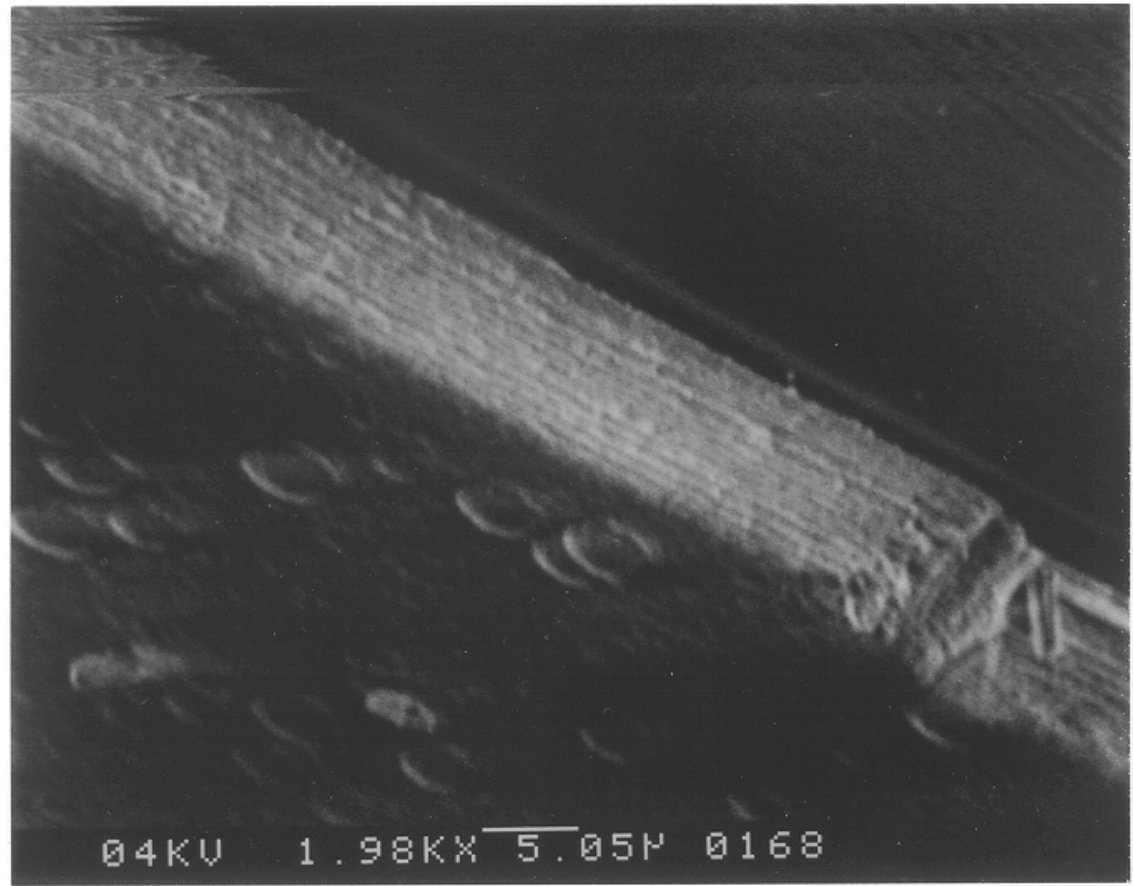

Fig. 3. Scanning electron microscope image of composite bi-layered EL film. 


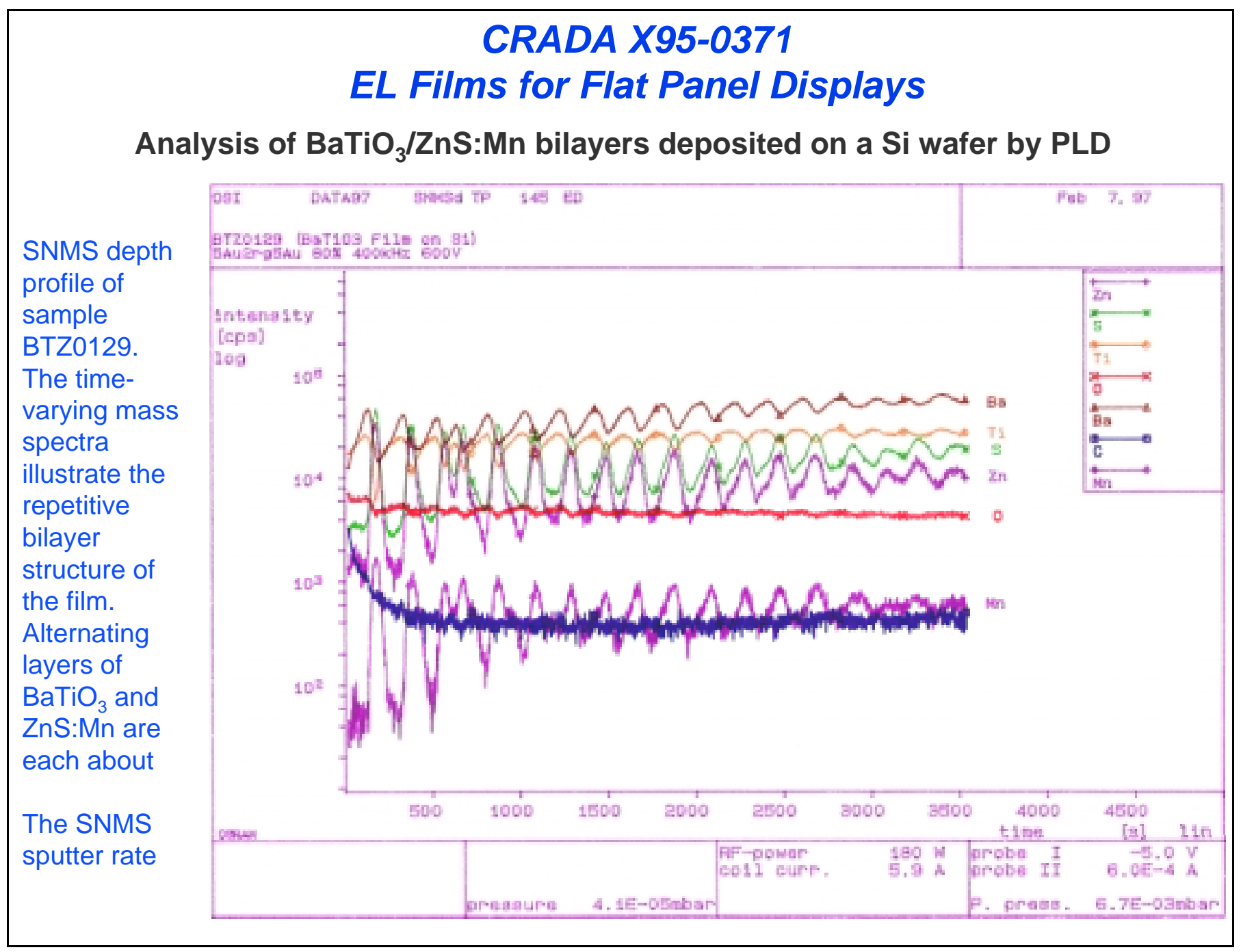

Fig. 4. Sputtered neutral mass spectrometer scan of sample BTZ 0129. 
Table 1. List of composite EL films fabricated and tested during CRADA project.

\begin{tabular}{|c|c|c|c|c|c|c|}
\hline $\begin{array}{c}\text { Sample } \\
\text { Designation }\end{array}$ & $\begin{array}{c}\text { Sample } \\
\text { Preparation Date }\end{array}$ & $\begin{array}{c}\text { Substrate } \\
\text { Material } \\
\end{array}$ & $\begin{array}{c}\text { Substrate } \\
\text { Temperature }\end{array}$ & $\begin{array}{c}\text { Background } \\
\text { Gas } \\
\end{array}$ & Film Structure and Composition & $\begin{array}{c}\text { Sample } \\
\text { Test Date }\end{array}$ \\
\hline NB474-75-1 & $8 / 6 / 96$ & Si wafer & $635^{\circ} \mathrm{C}$ & $100 \mathrm{mTorr}_{2}$ & Mono-layer $\mathrm{BaTiO}_{3}$ & $8 / 23 / 96$ \\
\hline NB474-75-2 & $8 / 7 / 96$ & Si wafer & 245 & 14 mTorr $\mathrm{N}_{2}$ & Mono-layer ZnS:Mn & $8 / 23 / 96$ \\
\hline NB474-75-3 & $8 / 13 / 96$ & Si wafer & 450 & $\begin{array}{c}100 \text { mTorr } \mathrm{O}_{2}, \\
5 \text { mTorr } \mathrm{N}_{2}\end{array}$ & Bi-layer $\mathrm{BaTiO}_{3}+\mathrm{ZnS}: \mathrm{Mn}$ & $8 / 23 / 96$ \\
\hline L027-5 & $12 / 7-9 / 96$ & Si wafer & 450 & $\begin{array}{l}145 \text { mTorr } \mathrm{O}_{2} \text {, } \\
145 \text { mTorr } \mathrm{N}_{2}\end{array}$ & Bi-layer $\mathrm{BaTiO}_{3}+\mathrm{ZnS}: \mathrm{Mn}$ & $1 / 6 / 97$ \\
\hline BTZ 129 & $1 / 27-28 / 97$ & Si wafer & 250 & $\begin{array}{l}140 \text { mTorr } \mathrm{O}_{2} \text {, } \\
140{\text { mTorr } \mathrm{N}_{2}}^{2}\end{array}$ & Repetitive bi-layer $\mathrm{BaTiO}_{3}+\mathrm{ZnS}: \mathrm{Mn}$ & $2 / 7 / 97$ \\
\hline BTZ 205 & $2 / 5 / 97$ & Si wafer & 450 & $\begin{array}{c}140 \text { mTorr } \mathrm{O}_{2}, \\
65 \text { mTorr } \mathrm{N}_{2}\end{array}$ & Repetitive bi-layer $\mathrm{BaTiO}_{3}+\mathrm{ZnS}: \mathrm{Mn}$ & $2 / 28 / 97$ \\
\hline BTZ 214 & $2 / 14 / 97$ & quartz flat & 450 & $\begin{array}{l}140 \text { mTorr } \mathrm{O}_{2}, \\
140 \mathrm{mTorr}_{2}\end{array}$ & Repetitive bi-layer $\mathrm{BaTiO}_{3}+\mathrm{ZnS}: \mathrm{Mn}$ & not tested \\
\hline BTZ 218 & $2 / 18-19 / 96$ & quartz flat & 450 & $\begin{array}{l}140 \text { mTorr } \mathrm{O}_{2}, \\
140 \text { mTorr }_{2}\end{array}$ & Repetitive bi-layer $\mathrm{BaTiO}_{3}+\mathrm{ZnS}: \mathrm{Mn}$ & not tested \\
\hline BTZC 311 & $3 / 11-12 / 97$ & Si wafer & 450 & $\begin{array}{l}145 \text { mTorr } \mathrm{O}_{2}, \\
145 \text { mTorr } \mathrm{N}_{2}\end{array}$ & Repetitive tri-layer $\mathrm{BaTiO}_{3}+\mathrm{ZnS}: \mathrm{Mn}+$ proprietary & $4 / 14 / 97$ \\
\hline BTZC 0404 & $4 / 4 / 97$ & Si wafer & 450 & $\begin{array}{l}140 \text { mTorr } \mathrm{O}_{2} \text {, } \\
140{\text { mTorr } \mathrm{N}_{2}}^{2}\end{array}$ & Repetitive tri-layer $\mathrm{BaTiO}_{3}+\mathrm{ZnS}: \mathrm{Mn}+$ proprietary & $5 / 16 / 97$ \\
\hline BTZC 0410 & $4 / 10 / 97$ & Si wafer & 450 & 140 mTorr $_{2}$ & Repetitive tri-layer $\mathrm{BaTiO}_{3}+\mathrm{ZnS}: \mathrm{Mn}+$ proprietary & $5 / 22$ \\
\hline ZC 0430 & $4 / 30 / 97$ & Si wafer & $517-592$ & 160 mTorr $\mathrm{N}_{2}$ & Repetitive bi-layer $\mathrm{ZnS}: \mathrm{Mn}+$ proprietary & not tested \\
\hline $\mathrm{ZC} 0506$ & $5 / 6-7 / 97$ & Si wafer & 100 & 175 mTorr $_{2}$ & Repetitive bi-layer ZnS:Mn + proprietary & not tested \\
\hline $\mathrm{ZC} 0522$ & $5 / 22 / 97$ & Si wafer & 450 & 160 mTorr $_{2}$ & Repetitive bi-layer ZnS:Mn + proprietary & $9 / 8 / 97$ \\
\hline BTZC 0617 & $6 / 17-23 / 97$ & quartz flat & 450 & 140 mTorr $_{2}$ & Repetitive tri-layer $\mathrm{BaTiO}_{3}+\mathrm{ZnS}: \mathrm{Mn}+$ proprietary & $8 / 28 / 97$ \\
\hline ZC 0627 & $6 / 27 / 97$ & Si wafer & 154 & 143 mTorr $_{2}$ & Repetitive bi-layer $\mathrm{ZnS}: \mathrm{Mn}+$ proprietary & $8 / 28 / 97$ \\
\hline BTZC 0811 & $8 / 8-11 / 97$ & Si wafer & 300 & $\begin{array}{l}120 \text { mTorr } \mathrm{O}_{2}, \\
120 \mathrm{mTorr}_{2}\end{array}$ & Repetitive tri-layer $\mathrm{BaTiO}_{3}+\mathrm{ZnS}: \mathrm{Mn}+$ proprietary & 9/30/97 \\
\hline BTZC 1007 & $10 / 7-8 / 97$ & Si wafer & 350 & $\begin{array}{l}200 \text { mTorr } \mathrm{O}_{2}, \\
200 \mathrm{mTorr}_{2} \\
\end{array}$ & Repetitive tri-layer $\mathrm{BaTiO}_{3}+\mathrm{ZnS}: \mathrm{Mn}+$ proprietary & not tested \\
\hline
\end{tabular}




\section{RESULTS}

The goals of the CRADA project were partially achieved. The overall goal of the project was to develop an improved EL material that is 10 times brighter than conventional EL materials. This goal was contingent on our ability to first demonstrate that electroluminescence can be obtained from the proposed composite EL material. We did indeed demonstrate a proof-of-principle of the composite EL material, but further work beyond this CRADA will need to be done to achieve the overall goal.

Achieving the proof-of-principle required the invention of an enabling process that was not conceptualized at the start of the CRADA. This enabling process has been disclosed as intellectual property developed jointly by ORNL and OSI.

\section{CONCLUSIONS}

\section{Commercialization Possibilities}

A recent market review of the flat panel display (FPD) industry performed by OSI indicated that liquid crystal diode-based displays (LCD's) are dominating 90\% of the FPD market. These LCD display devices, which are primarily monochromatic, use conventional electroluminescent film technology for backlighting. Conventional EL films are suitable for monochromatic LCD's because these LCD's have an opacity of approximately 30\%. By the year 2005, the FPD display industry will move toward color LCD technology that will require an entirely new class of EL materials. Color LCD's have an opacity of about 3\%, thus for backlighting they will require EL films that are ten times brighter than the current state-of-the-art EL films. The competing backlighting technology, fluorescent lighting, is very problematic. Fluorescent backlighting is prone to catastrophic failure and is not rugged enough for portable FPD devices. OSI estimates that by the year 2005, the worldwide market for FPD's will be \$20-40 billion, and the market opportunity for EL backlighting will be $\$ 1$ billion.

Thus there is considerable reason to continue the development of the composite EL material and to foresee its ultimate commercialization for the flat panel display industry.

Plans for the Future

ORNL and OSI plan to continue a joint development of the composite EL material. Proposals for future work have been submitted to the DOE Office of Energy Research and to the Defense Advanced Research Projects Administration. Future work will focus on improvements in the composite EL material through iterative design and characterization, development of advanced processes for rapid and efficient prototyping of artificially structured materials, and theoretical modeling and simulation of EL device structures. 


\section{REFERENCES}

1 "Method for making a composite electroluminescent phosphor," R. E. Karem and R. G. W. Gingerich, U.S. Patent 5,294,368, issued March 15, 1994.

2 “Composite electroluminescent phosphor," R. E. Karem and R. G. W. Gingerich, U.S. Patent 5,431,851, issued July 11, 1995.

3 "Multiple target laser ablation system," D. N. Mashburn, U.S. Patent 5,483,037, issued Jan. 9, 1996; "Dual beam optical system for pulsed laser ablation film deposition," D. N. Mashburn, U.S. Patent 5,558,788, issued Sep. 24, 1996.

${ }^{4}$ Progress Report for CRADA No. ORNL95-0371 with OSRAM Sylvania, Inc., "Electroluminescent Material For Flat Panel Display," July 31, 1995, through July 31, 1996 (unpublished). 


\section{Fhel Fojort eurtilotion tor

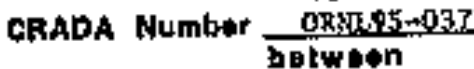

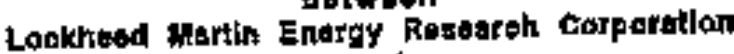 Uftit}

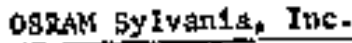

[Partlelpant)

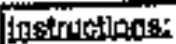

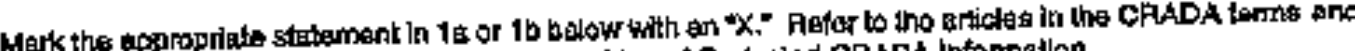

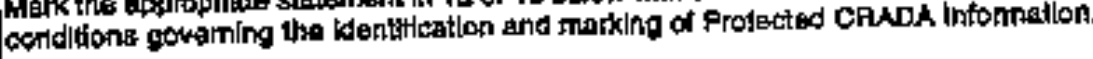

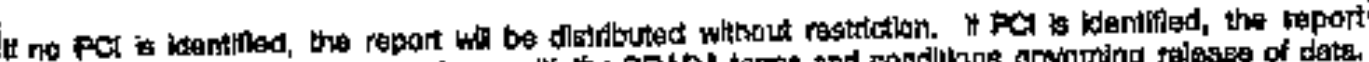

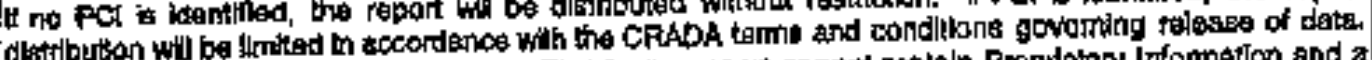

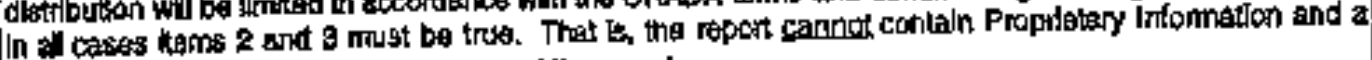
diteclesure mistil be files priar to releago of the raport.

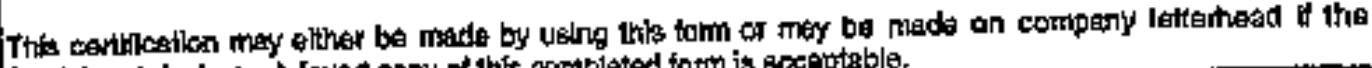

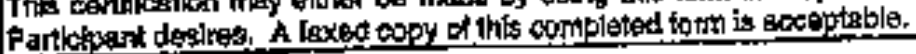

The tollowing certfiredton te made for the subject flnal report:

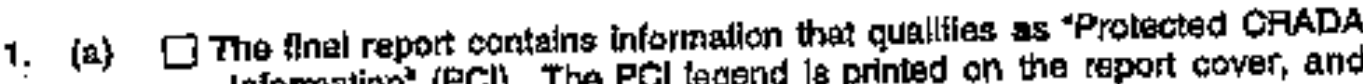
Iftomation (PC)). The Pol tegend le printed on the report cover, and the PCl is clearty ldenifiled.

QH

(b) Q The thal repoit does not contaln "Protected CAADA Iriometion." The "Approved for Pulale Relegse" legend he prirted an the report cover.

2. The finet report does not oontain Proprietary lintormletion.

3. By the elghature below, the Partcipent has no objectlon to the public dietributlon of the finat report dide to pateniable information.
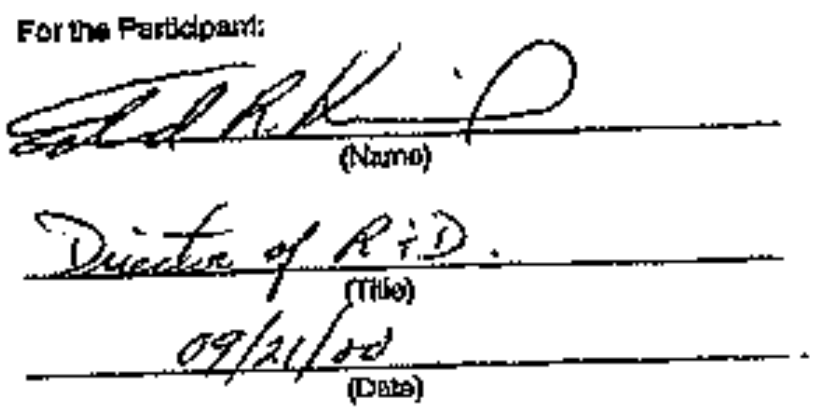